\title{
Effect of exercise on the proportion of unsaturated fatty acids in serum of untrained middle aged individuals
}

\author{
Vassilis Mougios, Evangelia Kouidi, Antonis Kyparos, Asterios Deligiannis
}

\begin{abstract}
Objectives-To examine whether prolonged moderate exercising by untrained middle aged individuals of both sexes affects the plasma ratio of unsaturated to saturated (U/S) fatty acids in the nonesterified fatty acid (NEFA) and triacylglycerol (TG) fractions.

Methods-Twenty two healthy untrained volunteers (eleven men and eleven premenopausal women), aged 35-55, exercised on bicycles at 50-55\% maximal heart rate reserve (estimated $61 \%$ maximal oxygen uptake) for one hour. Pre- and post-exercise blood samples were analysed for lactate, glucose, glycerol, individual NEFAs and TG acyl groups, cholesterol, high density lipoprotein cholesterol, urea, cortisol, and testosterone. Biopsy specimens of adipose tissue were analysed for TG acyl group composition.

Results-Serum total NEFAs increased significantly whereas total TG decreased significantly in both sexes. Changes in individual fatty acids, in both the NEFA and TG fractions, generally paralleled changes in the total pool but were not proportionate. As a result, U/S NEFAs increased in both sexes, although significantly only in women. The shift was in the direction of the composition of the major source of blood NEFAs-that is, adipose tissue TG. U/S acyl groups of TG also increased in both sexes, although significantly only in men.

Conclusions-Prolonged moderate exercise increases the U/S ratio of serum NEFAs and TG. This may add to the beneficial effects of exercise given the protective role of unsaturated fatty acids against coronary heart disease.

(BrF Sports Med 1998;32:58-62)
\end{abstract}

Department of

Physical Education

and Sports Science,

University of

Thessaloniki, Greece

V Mougios

E Kouidi

A Kyparos

A Deligiannis

Correspondence to: Dr V Mougios, TEFAA, University of Thessaloniki, 54006 Thessaloniki, Greece.

Accepted for publication 11 September 1997
Keywords: exercise; middle age; untrained individuals; unsaturated fatty acids; triacylglycerols

We have recently reported that, in adolescent male athletes, prolonged exercise of variable intensity caused significant acute increases in the plasma ratio of unsaturated to saturated (U/S) fatty acids in both the non-esterified fatty acid (NEFA) and triacylglycerol (TG) fractions. ${ }^{1}$ This finding may have interesting implications for health since unsaturated fatty acids are known to protect against coronary heart disease. ${ }^{2}{ }^{3}$
In the present study we examine whether similar changes accompany prolonged moderate exercising by individuals of both sexes who are older and physically less active and therefore at a higher risk for coronary heart disease than young athletes. In addition to the $\mathrm{U} / \mathrm{S}$ ratio, other biochemical parameters were measured for a more complete evaluation of the exercise protocol employed. Our results indicate that exercise can indeed increase the $\mathrm{U} / \mathrm{S}$ ratio in both the serum NEFA and TG fractions of untrained middle aged men and women.

\section{Subjects and methods}

Subjects were eleven men and eleven women who volunteered to participate in a project studying the effect of exercise on lipid metabolism. Inclusion criteria were: (a) age 35-55 years and (b) a low level of physical activity (no more than $2 \mathrm{~h}$ of exercise or $5000 \mathrm{~kJ}$ per week). Exclusion criteria were: (a) menopause, (b) apparent acute or chronic illness, (c) body mass above $140 \%$ of desirable mass (according to the 1985 NIH Consensus Panel Weight Table $\left.{ }^{4}\right),(d)$ smoking, (e) alcohol consumption above two drinks per day, and $(f)$ use of medication that might affect lipid metabolism, including oral contraceptives. The study was designed and carried out according to the guidelines of the university ethics committee.

At their preliminary visit to the laboratory, volunteers gave informed consent and filled in a health history questionnaire. Their body mass and height were measured and their percentage body fat was estimated from skinfold thickness measurements. ${ }^{5}$ The subjects then underwent physical examination to exclude cardiovascular disease and completed a graded maximal treadmill test ${ }^{6}$ during which oxygen uptake relative to body mass $\left(\dot{\mathrm{V}}_{2}\right)$ was monitored by a Cosmed K2 portable telemetry system (Cosmed, Rome, Italy). Finally, they were asked to record their dietary intake for three days including one weekend day. The dietary records were analysed for total energy, carbohydrate, fat, protein, and alcohol intake by using the Foodtabs (Sanders, London, United Kingdom) computer software.

Subjects came to the laboratory for the main test on a subsequent day, after an overnight fast, and gave a blood sample from an antecubital vein while in a sitting position. Subsequently they were asked to exercise on a cycle ergometer at gradually increasing velocity, reaching $50-55 \%$ of their maximal heart rate $(\mathrm{HR})$ reserve (defined as the difference 
Table 1 Characteristics of participants (mean (SEM))

\begin{tabular}{|c|c|c|c|c|}
\hline \multirow[b]{2}{*}{ Age (years) } & \multicolumn{2}{|c|}{$\operatorname{Men}(n=11)$} & \multicolumn{2}{|c|}{ Women $(n=11)$} \\
\hline & 41.9 & (1.6) & 44.5 & (1.1) \\
\hline Body mass (kg) & 81.4 & $(2.9)$ & 72.8 & $(4.4)$ \\
\hline Height (m) & 1.78 & $(0.02)$ & 1.62 & $(0.02)^{\star}$ \\
\hline Percent desirable body mass & 112 & (3) & 121 & (7) \\
\hline Body mass index $\left(\mathrm{kg} / \mathrm{m}^{2}\right)$ & 25.7 & $(0.7)$ & 27.7 & $(1.7)$ \\
\hline Percent body fat & 21.1 & (1.1) & 33.1 & $(1.1)^{\star}$ \\
\hline Resting HR (beats/min) & 66 & (3) & 73 & (2) \\
\hline Maximal HR (beats/min) & 183 & (2) & 176 & (2) \\
\hline$\dot{\mathrm{V}} \mathrm{O}_{2} \operatorname{MAX}(\mathrm{ml} / \mathrm{kg} / \mathrm{min})$ & 40.2 & (1.3) & 31.9 & $(2.0)^{\star \star}$ \\
\hline Energy intake (kJ/day) & 7568 & (901) & 5673 & $(450)$ \\
\hline Percent carbohydrate & 39.3 & (3.6) & 42.8 & (2.8) \\
\hline Percent fat & 40.2 & (2.3) & 38.5 & (1.8) \\
\hline Percent protein & 18.3 & (1.8) & 16.7 & (1.5) \\
\hline Percent alcohol & 2.1 & $(0.9)$ & 2.0 & $(0.7)$ \\
\hline
\end{tabular}

${ }^{\star} \mathrm{p}<0.001,{ }^{\star \star} \mathrm{p}<0.01$ : significantly different from the value for men.

Table 2 Characteristics of the exercise protocol (mean (SEM))

\begin{tabular}{|c|c|c|c|c|}
\hline & Men & & Women & \\
\hline Duration (min) & 60 & & 60 & \\
\hline Average HR (beats $/ \mathrm{min})^{\mathrm{a}}$ & 128 & (2) & 129 & (1) \\
\hline Percent maximal HR reserve & 53 & (0) & 54 & (1) \\
\hline Percent maximal HR & 70 & (1) & 73 & $(1)^{\star}$ \\
\hline Estimated $\dot{\mathrm{V}}_{2}(\mathrm{ml} / \mathrm{kg} / \mathrm{min})$ & 24 & (1) & 19 & $(1)^{\star \star}$ \\
\hline Percent $\dot{\mathrm{V}}_{2} \mathrm{MAX}$ & 61 & (1) & 61 & (3) \\
\hline Net energy cost $(\mathrm{kJ} / \mathrm{kg})$ & 23 & (2) & 18 & $(1)^{\star}$ \\
\hline Net energy cost (MJ) & 1.88 & $(0.11)$ & 1.34 & $4(0.12)^{\star}$ \\
\hline
\end{tabular}

aThe initial time during which subjects reached the target heart rate (HR) is not included in the averaging of HR but is included in the estimation of energy cost.

${ }^{\star} \mathrm{p}<0.05,{ }^{\star \star} \mathrm{p}<0.01$ : significantly different from the value for men.

between the maximal HR exhibited at the treadmill test and the resting HR) above resting $\mathrm{HR}$ within five minutes and to remain within that range for 55 minutes more. HR was monitored continuously by a Polar Accurex monitor (Polar Electro, Kempele, Finland). Blood was withdrawn as above within two minutes of termination of the test.

An aliquot of each pre- and post-exercise blood sample was mixed with heparin solution to measure packed cell volume and haemoglobin, while another aliquot was precipitated with perchloric acid $(0.3 \mathrm{~mol} / \mathrm{l})$ for lactate determination in the supernatant. The remaining blood was used to prepare serum for all other assays. Finally, a biopsy sample of subcutaneous adipose tissue was taken from the right buttock of each participant by needle aspiration. $^{7}$

Packed cell volume and haemoglobin were measured in an electronic counter to estimate changes in plasma volume. Whole blood lactate and serum glucose, glycerol, total cholesterol, high density lipoprotein (HDL) cholesterol, and urea were assayed by enzymic spectrophotometric methods using reagent kits from Boehringer (Mannheim, Germany). Individual serum NEFAs and TG acyl groups, as well as the acyl group composition of adipose tissue TG, were determined by a combination of thin layer chromatography and capillary gas chromatography as described. ${ }^{1}$ Total serum NEFAs were calculated as the sum of individual NEFAs, and total serum TG as the sum of individual TG acyl groups divided by three. All post-exercise serum cholesterol and TG values were corrected for changes in plasma volume as described. ${ }^{8}$ Cortisol and testosterone were measured by enzyme immunoassays with kits from CloneSystems (Bologna, Italy).

Values are expressed as the mean (SEM). Statistical comparisons were performed by applying appropriate Student's $t$ tests. Correlation between variables was examined by using Pearson's correlation coefficient. The level of significance $(p)$ was set at 0.05 .

\section{Results}

Table 1 gives the characteristics of the participants. Most characteristics, including age, body mass, percentage of desirable body mass, body mass index, resting HR, maximal HR, energy intake, and its distribution among the energy-providing nutrients were not significantly different between the sexes. On the other hand, height, percentage body fat, and maximal oxygen uptake relative to body mass $\left(\mathrm{Vo}_{2} \mathrm{MAX}\right)$ were significantly different between the sexes.

Men and women maintained similar average $\mathrm{HR}$ and percentages of maximal HR reserve during exercise (table 2). The cumulative mean values of the two parameters were 128 beats/minute and 53\% respectively. Based on the average HR during exercise and the relationship between $\mathrm{HR}$ and $\dot{\mathrm{V}}_{2}$ established during the maximal treadmill test, we estimated that exercise was performed at $61 \%$ $\dot{\mathrm{V}}_{\mathrm{O}_{2}} \mathrm{MAX}$. We also calculated the net energy cost of exercise by subtracting the resting $\dot{\mathrm{V}}_{2}$ from the exercise $\mathrm{V}_{2}$ and taking the energy equivalent of oxygen to be about $20 \mathrm{~kJ} /$ litre. Both $\dot{\mathrm{V}}_{2}$ and net energy cost were significantly higher in men than in women.

Table 3 lists the pre- and post-exercise serum values of the biochemical parameters determined. Lactate concentration increased slightly

Table 3 Pre- and post-exercise values of biochemical parameters of participants (mean (SEM))

\begin{tabular}{|c|c|c|c|c|c|c|}
\hline & \multicolumn{2}{|l|}{ Men } & \multicolumn{4}{|l|}{ Women } \\
\hline & Pre & Post & Pre & & Post & \\
\hline Lactate $(\mathrm{mmol} / \mathrm{l})$ & $1.17 \quad(0.10)$ & $1.83(0.20)^{\star}$ & 1.28 & $(0.08)$ & 1.69 & $(0.18)^{\star \star}$ \\
\hline Glucose (mmol/l) & $5.47 \quad(0.20)$ & $4.73(0.25)^{\star \star \star}$ & 5.16 & $(0.15)$ & 4.97 & $(0.17)^{\star \star}$ \\
\hline Glycerol (mmol/1) & $0.099(0.011)$ & $0.157(0.033)^{\star \star}$ & 0.097 & $(0.014)$ & 0.164 & $(0.023)^{\star}$ \\
\hline Total NEFA $(\mathrm{mmol} / \mathrm{l})$ & $0.424(0.032)$ & $0.530(0.071)^{\star \star}$ & 0.458 & $(0.034)$ & 0.670 & $(0.066)^{\star}$ \\
\hline Total TG $(\mathrm{mmol} / \mathrm{l})$ & $1.07(0.11)$ & $0.97(0.09)^{\star \star}$ & 0.78 & $(0.09)$ & 0.67 & $(0.07)^{\star \star}$ \\
\hline Total cholesterol $(\mathrm{mmol} / \mathrm{l})$ & $5.72(0.30)$ & $5.47(0.30)^{\star \star}$ & 5.73 & $(0.20)$ & 5.66 & $(0.20)$ \\
\hline HDL-cholesterol $(\mathrm{mmol} / \mathrm{l})$ & $1.09(0.09)$ & $1.07(0.09)$ & 1.43 & $(0.09)$ & 1.52 & $(0.10)$ \\
\hline Total/HDL-cholesterol & $5.60(0.48)$ & $5.50(0.50)$ & 4.18 & $(0.32)$ & 3.88 & $(0.29)$ \\
\hline Urea $(\mathrm{mmol} / \mathrm{l})$ & $6.34 \quad(0.37)$ & $6.30(0.38)$ & 5.91 & $(0.39)$ & 5.79 & $(0.39)$ \\
\hline Cortisol (nmol/1) & $(31)$ & (35) & 280 & (33) & 284 & (35) \\
\hline Testosterone $(\mathrm{nmol} / \mathrm{l})$ & $22.03(2.26)$ & $25.62(2.68)^{\star \star \star}$ & 2.14 & $(0.36)$ & 2.36 & $(0.33)$ \\
\hline
\end{tabular}

NEFA, non-esterified fatty acids; TG, triaclyglycerol; HDL, high density lipoprotein.

${ }^{\star} \mathrm{p}<0.01,{ }^{\star \star} \mathrm{p}<0.05,{ }^{\star \star \star} \mathrm{p}<0.001$ : significantly different from the pre-exercise value. 
Table 4 Pre-and post-exercise serum concentration and percentage molar distribution of non-esterified fatty acids (mean (SEM))

\begin{tabular}{|c|c|c|c|c|c|c|c|c|}
\hline \multirow[b]{2}{*}{ Fatty acid } & \multicolumn{4}{|l|}{ Men } & \multicolumn{4}{|l|}{ Women } \\
\hline & \multicolumn{2}{|l|}{ Pre } & \multicolumn{2}{|l|}{ Post } & \multicolumn{2}{|l|}{ Pre } & \multicolumn{2}{|l|}{ Post } \\
\hline \multicolumn{9}{|c|}{ Concentration $(\mu \mathrm{mol} / \mathrm{l})$} \\
\hline $14: 0$ & 9.2 & $(1.2)$ & 10.8 & $(2.1)$ & 8.2 & $(1.1)$ & 12.1 & $(1.2)^{\star}$ \\
\hline $16: 0$ & 123.2 & (12.4) & 151.4 & $(23.2)$ & 128.8 & $(8.0)$ & 184.1 & $(15.3)^{\star}$ \\
\hline $16: 1$ & 10.8 & $(1.6)$ & 14.5 & $(3.1)$ & 11.0 & $(1.0)$ & 18.8 & $(2.1)^{\star}$ \\
\hline $18: 0$ & 53.1 & $(4.0)$ & 54.9 & (5.4) & 63.7 & $(4.6)$ & 69.7 & $(6.4)$ \\
\hline $18: 1$ & 165.1 & (11.7) & 215.6 & $(29.1)^{\star \star}$ & 176.9 & (14.3) & 274.8 & $(27.5)^{\star \star \star}$ \\
\hline $18: 2$ & 56.7 & $(5.1)$ & 75.0 & $(11.3)$ & 63.4 & $(10.6)$ & 102.6 & $(17.7)^{\star}$ \\
\hline $18: 3$ & 0.3 & $(0.2)$ & 1.1 & $(0.5)$ & 0.6 & $(0.3)$ & 1.6 & $(0.8)$ \\
\hline $20: 4$ & 5.3 & $(0.4)$ & 6.5 & $(0.6)$ & 5.5 & $(0.6)$ & 6.6 & $(0.7)$ \\
\hline Total & 423.7 & (32.3) & 529.9 & $(70.5)^{\star \star}$ & 458.1 & $(34.4)$ & 670.2 & $(65.9)^{\star \star \star}$ \\
\hline \multicolumn{9}{|c|}{ Percentage molar distribution } \\
\hline $14: 0$ & 2.12 & $(0.12)$ & 1.97 & $(0.14)$ & 1.84 & $(0.26)$ & 1.85 & $(0.12)$ \\
\hline $16: 0$ & 28.70 & $(0.86)$ & 28.50 & $(0.97)$ & 28.49 & $(0.88)$ & 27.97 & $(0.64)$ \\
\hline $16: 1$ & 2.48 & $(0.22)$ & 2.58 & $(0.18)$ & 2.40 & $(0.10)$ & 2.79 & $(0.12)^{\star}$ \\
\hline 18:0 & 12.66 & $(0.55)$ & 10.96 & $(0.63)^{\star \star}$ & 14.19 & $(0.91)$ & 10.66 & $(0.58)^{\star}$ \\
\hline 18:1 & 39.27 & (1.07) & 40.59 & $(1.46)$ & 38.40 & (1.08) & 40.76 & $(1.29)^{\star \star}$ \\
\hline $18: 2$ & 13.38 & $(0.85)$ & 13.84 & $(1.06)$ & 13.32 & $(1.07)$ & 14.77 & $(1.07)^{\star}$ \\
\hline $18: 3$ & 0.07 & $(0.05)$ & 0.21 & $(0.10)$ & 0.10 & $(0.06)$ & 0.21 & $(0.07)^{\star \star}$ \\
\hline $20: 4$ & 1.33 & $(0.14)$ & 1.36 & $(0.15)$ & 1.25 & $(0.15)$ & 1.00 & $(0.05)$ \\
\hline $\mathrm{U} / \mathrm{S}$ & 1.30 & $(0.033)$ & 1.436 & $(0.074)$ & 1.265 & $(0.064)$ & 1.489 & $(0.065)^{\star \star \star}$ \\
\hline
\end{tabular}

$\mathrm{U} / \mathrm{S}$, unsaturated/saturated.

${ }^{\star} \mathrm{p}<0.001,{ }^{\star \star} \mathrm{p}<0.05,{ }^{\star \star \star} \mathrm{p}<0.01$ : significantly different from the pre-exercise value.

although significantly with exercise (by 0.66 $\mathrm{mmol} / 1$ in men and $0.41 \mathrm{mmol} / 1$ in women), whereas glucose decreased significantly (by $14 \%$ in men and $4 \%$ in women). The decrease in glucose was significantly greater in men than in women $(\mathrm{p}<0.001)$. Glycerol increased significantly (by $59 \%$ in men and $69 \%$ in women) and so did the total NEFA concentration (by $25 \%$ in men and $46 \%$ in women). Total TG decreased significantly (by $9 \%$ in men and $14 \%$ in women). Total cholesterol decreased significantly in men only (by $4.4 \%$ ) whereas HDL-cholesterol did not change significantly in either sex. The ratio of total to HDLcholesterol tended to decrease but changes were not significant. Urea did not change significantly in either sex neither did cortisol. Testosterone increased significantly in men only (by $16 \%$ ).

Table 4 (upper half) contains the pre- and post-exercise concentrations of the eight NEFAs detected in the participants' serum, i.e. myristate (14:0; carbon atoms:double bonds), palmitate (16:0), palmitoleate (16:1), stearate $(18: 0)$, oleate $(18: 1)$, linoleate $(18: 2)$, linolenate (18:3), and arachidonate (20:4). The only significant change observed in men was an increase in 18:1. Women, on the other hand, exhibited significant increases in five NEFAs (14:0, 16:0, 16:1, 18:1, and 18:2). To facilitate comparisons, changes in these and the following parameters are depicted schematically in fig 1 .

From the concentrations of the individual NEFAs, we calculated their percentage molar distribution (Table 4, lower half). In men, the only significant change was a decrease in 18:0. Women exhibited a higher number of significant changes: the percentages of four NEFAs (16:1, 18:1, 18:2, and 18:3) increased, whereas the percentage of 18:0 decreased. As a result of the opposite changes in the relative amounts of unsaturated and saturated NEFAs in women, their ratio increased

Table 5 Pre-and post-exercise serum concentration and percentage molar distribution of triacylglycerol (TG) acyl groups (mean (SEM))

\begin{tabular}{|c|c|c|c|c|c|c|c|c|}
\hline \multirow[b]{2}{*}{ Fatty acid } & \multicolumn{4}{|l|}{ Men } & \multicolumn{4}{|l|}{ Women } \\
\hline & \multicolumn{2}{|l|}{ Pre } & \multicolumn{2}{|l|}{ Post } & \multicolumn{2}{|l|}{ Pre } & \multicolumn{2}{|l|}{ Post } \\
\hline \multicolumn{9}{|c|}{ Concentration $(\mu \mathrm{mol} / \mathrm{l})$} \\
\hline $14: 0$ & 68 & (7) & 55 & $(6)^{\star}$ & 51 & (9) & 36 & (7) \\
\hline $16: 0$ & 875 & (105) & 766 & $(77)^{\star \star}$ & 680 & (85) & 563 & $(70)^{\star \star}$ \\
\hline $16: 1$ & 103 & (17) & 90 & $(13)^{\star \star}$ & 80 & (12) & 63 & (9) \\
\hline $18: 0$ & 118 & (15) & 104 & (9) & 102 & (10) & 86 & $(8)^{\star \star}$ \\
\hline $18: 1$ & 1377 & (157) & 1262 & (128) & 985 & (121) & 866 & $(94)^{\star \star}$ \\
\hline $18: 2$ & 610 & $(68)$ & 582 & $(66)$ & 397 & $(64)$ & 353 & $(62)^{\star \star}$ \\
\hline $18: 3$ & 19 & (4) & 16 & (3) & 7 & (2) & 6 & (2) \\
\hline $20: 4$ & 33 & (4) & 33 & (4) & 26 & (4) & 27 & (4) \\
\hline Total & 3203 & (334) & 2908 & $(265)^{\star \star}$ & 2328 & (265) & 2000 & $(218)^{\star \star}$ \\
\hline Total TG & 1068 & (111) & 969 & $(88)^{\star \star}$ & 776 & $(88)$ & 667 & $(73)^{\star \star}$ \\
\hline \multicolumn{9}{|c|}{ Percentage molar distribution } \\
\hline $14: 0$ & 2.14 & $(0.12)$ & 1.92 & $(0.09)^{\star \star}$ & 2.20 & $(0.30)$ & 1.76 & $(0.21)$ \\
\hline $16: 0$ & 27.13 & $(1.35)$ & 26.40 & $(1.25)$ & 29.28 & $(1.23)$ & 28.26 & $(1.35)$ \\
\hline $16: 1$ & 3.15 & $(0.30)$ & 3.10 & $(0.28)$ & 3.35 & $(0.18)$ & 3.10 & $(0.12)$ \\
\hline $18: 0$ & 3.76 & $(0.28)$ & 3.65 & $(0.23)$ & 4.58 & $(0.38)$ & 4.54 & $(0.40)$ \\
\hline $18: 1$ & 43.03 & $(1.67)$ & 43.40 & $(1.51)$ & 42.29 & $(1.58)$ & 43.70 & (1.67) \\
\hline $18: 2$ & 19.17 & $(1.36)$ & 19.88 & $(1.37)^{\star}$ & 16.89 & $(1.86)$ & 17.09 & $(1.85)$ \\
\hline $18: 3$ & 0.57 & $(0.08)$ & 0.51 & $(0.08)$ & 0.29 & $(0.09)$ & 0.25 & $(0.08)$ \\
\hline $20: 4$ & 1.04 & $(0.11)$ & 1.11 & $(0.10)$ & 1.12 & $(0.12)$ & 1.30 & $(0.13)$ \\
\hline $\mathrm{U} / \mathrm{S}$ & 2.096 & $(0.150)$ & 2.196 & $(0.155)^{\star \star}$ & 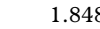 & $(0.159)$ & 1.979 & $(0.174)$ \\
\hline
\end{tabular}

$\mathrm{U} / \mathrm{S}$, unsaturated/saturated.

${ }^{\star} \mathrm{p}<0.01,{ }^{\star \star} \mathrm{p}<0.05$ : significantly different from the pre-exercise value. 

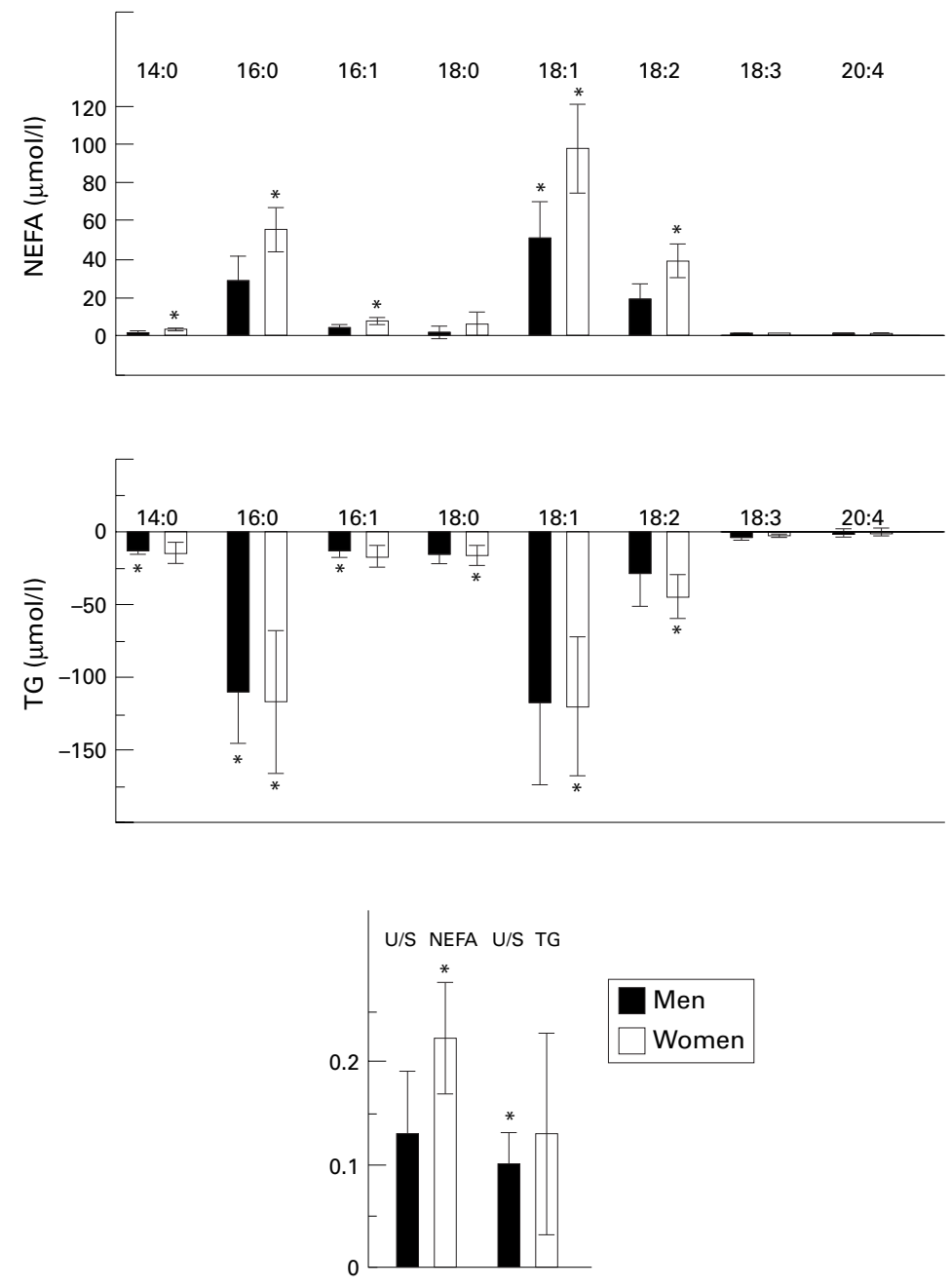

Figure 1 Changes in concentration of individual serum non-esterified fatty acids (NEFAs) and triacylglycerol (TG) acyl groups, as well as in the unsaturated/saturated $(U / S)$ ratio in men and women. Asterisks indicate significant changes.

significantly (by $18 \%$, Table 4 , lower half). There was also a $10 \%$ increase in U/S NEFAs in men which just misses statistical significance $(p=0.06)$.

Table 5 presents the pre- and post-exercise serum concentrations and percentage molar distributions of TG acyl groups. Significant decreases in the concentrations of three or four of the eight fatty acids were found in both sexes. The most consistent change was a decrease in 16:0. As far as the percentage molar distribution of TG acyl groups is concerned, the only significant changes were a decrease in 14:0 and an increase in 18:2 in men. Finally, $\mathrm{U} / \mathrm{S}$ TG acyl groups increased in both sexes (by $5-7 \%$ ), but only the change in men reached statistical significance.

The shift toward unsaturated NEFAs observed in men and women with exercise was in the direction of the composition of the major source of blood NEFAs - that is, adipose tissue TG. The U/S ratio of the latter (table 6) was significantly higher than any U/S ratio in table $4(\mathrm{p}<0.001)$. Moreover, changes in U/S NEFAs correlated positively with changes in
Table 6 Percentage molar distribution of acyl groups in adipose tissue triacylglycerol (mean (SEM))

\begin{tabular}{lrlrl}
\hline Fatty acid & \multicolumn{3}{c}{ Men } & \multicolumn{3}{c}{ Women } \\
\hline $14: 0$ & 2.15 & $(0.17)$ & 2.00 & $(0.11)$ \\
$16: 0$ & 22.23 & $(0.57)$ & 20.92 & $(0.57)$ \\
$16: 1$ & 4.38 & $(0.33)$ & 5.51 & $(0.35)^{\star}$ \\
$18: 0$ & 4.18 & $(0.23)$ & 3.28 & $(0.20)^{\star \star}$ \\
$18: 1$ & 50.94 & $(0.78)$ & 51.93 & $(1.01)$ \\
$18: 2$ & 15.34 & $(0.56)$ & 15.65 & $(0.82)$ \\
$18: 3$ & 0.38 & $(0.02)$ & 0.36 & $(0.03)$ \\
$20: 4$ & 0.40 & $(0.05)$ & 0.35 & $(0.05)$ \\
U/S & $2.531(0.100)$ & 2.849 & $(0.118)$ \\
\hline
\end{tabular}

$\mathrm{U} / \mathrm{S}$, unsaturated/saturated.

${ }^{\star} \mathrm{p}<0.05,{ }^{\star \star} \mathrm{p}<0.01$ : significantly different from the value for men.

total NEFA concentration (correlation coefficient $0.65, \mathrm{p}=0.001, \mathrm{n}=22$ ).

\section{Discussion}

We have determined acute changes in a number of biochemical parameters of blood - with emphasis on serum lipids - caused by one hour of cycling at $53 \%$ maximal $\mathrm{HR}$ reserve or $61 \%$ $\dot{\mathrm{V}}_{2} \mathrm{MAX}$ upon untrained middle aged men and women. This exercise protocol stimulated adipose tissue lipolysis as evidenced by the significant increases in both serum glycerol and total NEFA concentrations. However, the increases in individual NEFA concentrations were not proportionate as shown by the significant changes in the percentages of several of them. Remarkably, the percentages of saturated NEFAs decreased, whereas those of unsaturated NEFAs increased (table 4). As a result, the NEFA U/S ratio increased. This change correlated positively with the change in total NEFA concentration, suggesting that the higher the release of fatty acids from adipose tissue TG, the greater the shift toward unsaturated NEFAs. The correlation can be explained by the acyl group composition of TG from the participants' subcutaneous adipose tissue, where the U/S ratio was about twice that of serum NEFAs. This ratio can be taken only as indicative since adipose tissue exhibits regional differences in fatty acid composition ${ }^{910}$ and in the lipolytic response to exercise ${ }^{11}$ as well as gender differences in distribution throughout the body.

Total serum TG concentration decreased significantly in both sexes. This confirms the generally recognised potential of a single bout of exercise to induce transient decreases in $\mathrm{TG},{ }^{12}$ although several studies on untrained men who performed bicycle exercise at intensities and duration similar to ours found no significant effect on TG concentration. ${ }^{13-16}$ We could not trace any pertinent studies on women. The decreases in total TG concentration in our study were accompanied by increases in U/S acyl groups. Since changes in plasma TG concentration in the post-absorptive state reflect changes in the balance between output by the liver and hydrolysis by lipoprotein lipase and hepatic TG lipase, an increase in U/S acyl groups in the face of decreasing TG concentration suggests a selectivity of the combined activity of these two lipases toward saturated acyl groups.

Changes in cholesterol and its HDL fraction were not as clear-cut as changes in TG in our study, in agreement with most similar studies 
cited above..$^{13} 1416$ There was, however, a tendency towards a lower ratio of total to HDL-cholesterol.

We have included urea as an index of amino acid metabolism and two hormones (cortisol and testosterone) with opposite metabolic effects on skeletal muscle proteins (catabolic and anabolic respectively) in our evaluation of the exercise protocol. Most changes in these parameters were not significant, therefore we can assume that protein metabolism was not considerably affected.

In our previous study of the effect of exercise on the composition of plasma NEFAs and TG we found an increase in U/S NEFAs of $49 \%$, concomitant with an increase in total NEFA concentration of $229 \%$, and an increase in U/S acyl groups of TG by $8 \%$ accompanying a decrease in total TG concentration of $22 \%$. ${ }^{1}$ All of those changes were greater than the corresponding changes in the present paper. Mode of exercise, training state, body composition, and age may be responsible for these differences. Nevertheless, changes are in the same direction in both of our studies. We therefore conclude that untrained middle aged men and women, as well as adolescent male athletes, experience an increase in U/S ratio in both the serum NEFAs and TG fractions with prolonged moderate exercise.

The physiological significance of the above findings is not known. We are currently investigating the duration of the observed changes and whether there are chronic effects of exercise training on U/S ratios. Such research should enable the importance of the increase in the proportion of unsaturated serum fatty acids for lowering the risk of coronary heart disease to be evaluated.

1 Mougios V, Kotzamanidis C, Koutsari C, Atsopardis S. Exercise-induced changes in the concentration of individual fatty acids and triacylglycerols of human plasma. Metabolism 1995;44:681-8.

Metabolism 1995;44:681-8.
2 NIH Consensus Conference. Triglyceride, high-density lipoprotein, and coronary heart disease. $\mathcal{F} A M A$ 1993;269: 505-10.

3 Gurr MI, Borlak N, Ganatra S. Dietary fat and plasma lipids. Nutrition Research Reviews 1989;2:3-86.

4 Nieman DC. Fitness and sports medicine: an introduction. Palo Alto: Bull Publishing Co., 1990:508.

5 Jackson AS, Pollock ML. Practical assessment of body composition. Physician and Sportsmedicine 1985;13:76-90.

6 Bruce RA. Multi-stage treadmill test of submaximal and maximal exercise. In: Exercise testing and training of maximal exercise. In: Exercise testing and training of apparently healthy individuals: a handbook for phys

7 Beynen AC, Katan MB. Rapid sampling and long-term storage of subcutaneous adipose-tissue biopsies for determination of fatty acid composition. Am f Clin Nutr 1985;42:317-22

8 Dill DB, Costill DL. Calculation of percentage changes in volume of blood, plasma, and red cells in dehydration. $f$ Appl Physiol 1974;37:247-8.

9 Calder PC, Harvey DJ, Pond CM, Newsholme EA. Site-specific differences in the fatty acid composition of human adipose tissue. Lipids 1992;27:716-20.

10 Phinney SD, Stern JS, Burke KE, et al. Human subcutaneous adipose tissue shows site-specific differences in fatty acid composition. Am f Clin Nutr 1994;60:725-9.

11 Arner P. Regulation of lipolysis in exercise studied by microdialysis. In: Maughan RJ, Shirreffs SM, eds. Biochemistry of dialysis. In: Maughan RJ, Shirreffs SM, eds. Biochemistry

12 Pronk NP. Short-term effects of exercise on plasma lipids Pronk NP. Short-term effects of exercise on plasma lipid
and lipoproteins in humans. Sports Med 1993;16:431-48.

13 Cullinane E, Lazarus B, Thompson PD, et al. Acute effects of a single exercise session on serum lipids in untrained men. Clin Chim Acta 1981;109:341-4.

14 Cullinane E, Siconolfi S, Saritelli A, Thompson PD. Acute decrease in serum triglycerides with exercise: is there a threshold for an exercise effect? Metabolism 1982;31:844-7.

15 Kantor MA, Cullinane EM, Sady SP, et al. Exercise acutely increases high density lipoprotein-cholesterol and lipoprotein lipase activity in trained and untrained men. Metabolism 1987;36:188-92.

16 Tefft LR, Fernhall B. Lack of acute blood lipid changes following prolonged exercise in subjects with and without coronary heart disease. Fournal of Cardiopulmonary Rehabilitation 1993;13:432-8. 